\title{
Proceso de armonización del derecho privado en América Latina*
}

\author{
Sindy V. Medina Velandia** \\ Rodrigo A. Plazas Estepa
}

Recibido: 3 de febrero de 2016 • Revisado: 18 de febrero de 2016

Aprobado: 23 de febrero de 2016

\section{Resumen}

El presente trabajo parte de la pregunta ¿cuáles son las perspectivas y posibilidades de un proceso de armonización del derecho privado en América Latina? Para lo cual inicialmente se analiza la noción de armonización y sus principales características, avanzando enseguida con un diagnóstico sobre los principales problemas que se evidencian en América Latina. Con este análisis se procede enseguida a identificar el proceso histórico que se ha venido desarrollando en América Latina sobre la armonización, específicamente en el derecho privado, para finalizar identificando los principales elementos o factores que se deben tener en cuenta para la armonización y unificación del derecho privado en América Latina.

Palabras clave: Armonización legislativa, ordenamiento jurídico, sistema jurídico.

" El documento es producto del Proyecto de Investigación titulado: Armonización del derecho internacional de marcas para el caso colombiano del Grupo de Investigación en Derecho Económico y Estado de la Corporación Universitaria Republicana. El citado proyecto fue financiado por la Academia en mención.

* Abogada y especialista en Derecho de Familia y Conciliadora en derecho de la Corporación Universitaria Republicana; Doctoranda en Derecho de la UBA. Docente Investigador del Grupo de Investigación Derecho Económico y Estado de la Corporación Universitaria Republicana. Correo electrónico: sindy-meve@urepublicana.edu.co.

**o Abogado y Magister en Derecho de la Universidad Sergio Arboleda y Doctorando en Derecho de la UBA. Director del Centro de Investigaciones y Docente Investigador del Grupo de Investigación Derecho Económico y Estado de la Corporación Universitaria Republicana. Correo electrónico: rodrigoplazas@urepublicana.edu.co. 


\title{
Process of harmonization of PRivate LAW in Latin America
}

\begin{abstract}
This paper begins with the question: What are the prospects and possibilities of a process of harmonization of private law in Latin America? for which initially the notion of harmonization and its main characteristics is analyzed, moving quickly with a diagnosis of the main problems that are evident in Latin America. This analysis is immediately proceeds to identify the historical process that has been developing in Latin America on harmonization, particularly in private law, to finish identifying the main elements or factors to consider for the harmonization and unification of law private in Latin America.
\end{abstract}

Keywords: Legislative harmonization, legal system.

\section{Processo de harmonização do direito PRiVAdo na América Latina}

\section{Resumo}

O presente trabalho sai a partir da pergunta ¿quais são as perspectivas e possibilidades de um processo de harmonização do direito privado na América Latina? Para isto inicialmente é analisada a noção de harmonização e de suas principais características, avançando logo após com um diagnóstico referente dos principais problemas que são evidenciados na América Latina. Com esta análise de imediato prossegue-se para identificar o processo histórico que tem vindo a desenvolver na América Latina em matéria de harmonização, nomeadamente no direito privado, para concluir identificando os principais elementos ou fatores que devem ser levados em conta para a harmonização e uniformização do direito privado na América Latina.

Palavras-chave: Harmonização legislativa, ordem jurídica, sistema legal.

\section{Introducción}

La armonización legislativa es un proceso en el cual las barreras entre los sistemas jurídicos tienden a desaparecer, mediante la incorporación de normas comunes o 
similares para establecer un verdadero marco jurídico comunitario; y que supone el establecimiento de objetivos comunes, que involucra temas económicos, sociales, culturales y políticos; los cuales evolucionan en la medida en que se fortalecen los vínculos entre los diferentes sistemas jurídicos que se buscan integrar.

Es desde la citada perspectiva que se pretende analizar el marco de la armonización normativa en algunos aspectos propios de Latinoamérica, para lo cual se empleó la metodología de investigación cualitativa en el contexto del método narrativo.

\section{Acercamiento general a la noción de armonización normativa}

La noción de armonización en el ámbito jurídico o normativo se encuentra enmarcada y delimitada por el contexto histórico en el cual se hace presente, lo que implica que es un concepto dinámico, aun cuando es claro que conserva una serie de características que lo identifican independientemente del momento histórico en el cual se encuentre. En ese sentido, Momberg (2009) plantea que la armonización normativa es un proceso orientado a buscar la conformidad legislativa en el tratamiento de un asunto o tema que se encuentra disperso, lo que permite que se pueda establecer un sistema normativo coherente y consistente.

Profundizando, Serna (2007) plantea, desde la perspectiva de un sistema federal, que la armonización es "el proceso por el cual el derecho local en una entidad determinada se llega a asemejar al derecho de otras entidades federadas, al tiempo que conserva su identidad propia como derecho local" (p. 798). La importancia de esta definición radica en que aporta dos elementos fundamentales; por un lado se trata ante todo del interés por asemejar o asimilar unas determinadas normas que se encuentran disgregadas, pero, por otro lado, que dicho proceso no implica la pérdida de su identidad; es decir que para el presente caso los Estados no dejan al margen su derecho local, aun cuando es claro que genera una mayor consistencia.

Desde otro enfoque, Bermúdez (2006) define la armonización como la una unión de ponderaciones o consideraciones de índole jurídica y de mayor flexibilidad que la unificación, ya que no implica necesariamente la "adopción de un texto uniforme; se refiere más bien a una simple aproximación de criterios jurídicos, apoyándose en bases, leyes modelos, o doctrina común, que pueden servir de punto de partida para que los legisladores y jueces nacionales puedan coordinar el enfoque jurídico de un conflicto de intereses determinado" (p. 132). 
Finalmente, partiendo de las evidentes diferencias entre los Estados latinoamericanos en aspectos jurídicos, culturales, sociales, económicos y políticos; pero a la vez constatando que también existen elementos o factores que permiten una identidad como región; Tito (2013) plantea que la armonización normativa es un proceso de integración en la diversidad, lo que implica que su dinámica se basa en un "modelo de integración jurídico-flexible o lo que es igual, en un modelo de complejidad que adapta las mutaciones que sufre el derecho dentro de un sistema y entorno jurídico siempre heterogéneos" (p. 248).

\section{Problemática de la armonización normativa en América Latina}

Entendiendo estos elementos conceptuales sobre la armonización normativa, es de señalar que la problemática relativa a este tema se encuentra circunscrita por la actual sociedad, caracterizada por la globalización como mecanismo para guiar las relaciones en todos los ámbitos de la vida pública y privada (Sánchez, 2008), generando como consecuencia que en el ámbito jurídico, incluido el Derecho privado, se reflexione sobre la importancia de llevar a cabo procesos de normalización internacional, llegando inclusive a adoptarse procesos de unificación legislativa orientada a la protección de los diferentes actores que intervienen en los negocios, ya sea la índole que sea (comercial, civil).

Esto obedece ante todo a que se presentan de forma permanente conflictos jurídicos entre partes que pertenecen a diferentes Estados, lo que genera en muchos de los casos que se presenten vacíos jurídicos a la hora de fallar en justicia, pero incluyendo la posibilidad de crear mecanismos alternativos de resolución de conflictos (García, 2002).

Es pues la globalización un fenómeno que viene incidiendo de forma profunda en la organización de la sociedad a nivel mundial, en tanto personas, comunidades $y$ regiones se encuentran insertas en un proceso permanente de interrelaciones que superan los límites geográficos y políticos que a lo largo de la historia han venido funcionando en las sociedades. Aun así, se expresa que no se puede hablar de una globalización absoluta, en la medida que hay una fuerte incidencia en el concepto cultural de identidad nacional, así como de la clara presencia de diversidades culturales y sociales que caracterizan a determinadas comunidades y que no se puede soslayar (Álvarez, Giacalone y Sandoval, 2002). 
Ni la unificación del Derecho ni el proceso de la globalización podrían extinguir un hecho natural y espontáneo como la variedad en las identidades nacionales; faltaría mucho por suceder, o es casi imposible admitir una unificación absoluta que incluya órdenes de diversas índoles pues el ser humano como tal es complejo y divergente por naturaleza. (Bermúdez, 2006, p. 137)

Frente a este contexto, Suárez (2012) subraya que es esta misma realidad de la globalización la que hace posible la armonización y unificación del derecho privado en América Latina, en tanto existen esfuerzos que buscan preservar, unificar y difundir principios que lo orientan, y a su vez sirve como un mecanismo para frenar dicho avance de la globalización enfrentándolo con una propuesta regional. El problema ha sido que este proceso no se ha consolidado de forma contundente, lo que ha impedido que se estructure un derecho privado latinoamericano sólido.

Esto obedece a la incidencia de las grandes multinacionales que ven en estos países una oportunidad de negocios e inversión de fácil acceso y sin pocas barreras, lo que convierte la armonización en un imperativo jurídico para que se pueda materializar, en un solo vértice, "la complejidad de los diversos sistemas jurídicos, de tal forma que los pueblos, sus empresas y organizaciones lleguen a ser más competitivas en el terreno global" (Suárez, 2012, p. 54).

\section{Elementos históricos}

Sobre esta base problemática, es decir que la normalización del derecho privado en América Latina hunde sus raíces históricas en los procesos de independencia impulsadas a inicios del siglo XIX y que dio paso a diferentes formas de unificación territorial y jurisdiccional v. gr. La Gran Colombia, lo que puso en evidencia el notable interés por consolidar la soberanía en la región.

Simón Bolívar, en 1821, propuso la idea de reunir un congreso en que estuvieran representados los pueblos libres hispanoamericanos para que estableciesen una confederación, y los demás fundadores aceptaron este ideal como el motivo principal de su voluntad política. Así, decidieron reunir sus recursos y desarrollar armoniosamente un sistema de negocios internacionales, porque previeron la necesidad de proteger sus intereses, de satisfacer las necesidades de sus pueblos y dirimir sus 
conflictos de derecho público y privado mediante la creación de un tribunal internacional de justicia. (Suárez, 2012, p. 48)

Estas intenciones, como bien es sabido, no terminaron exitosamente, sino que contrario sensu concluyeron con la escisión y fracturación de la sociedad americana en cuantos Estados que se formaron por igual número de intereses particulares, aspecto que por el momento no se analiza con mayor profundidad, ya que no hace parte del presente estudio, pero que resulta vital para comprender su momento actual.

Conforme a Garro (1992) y Bermúdez (2006) son varios los factores históricos en América Latina que confluyen en el interés por un proceso de armonización profundo y consolidado, siendo entre otros:

- Identidad lingüística, geográfica, religiosa, costumbres y de problemas en los diversos ámbitos (social, político, económico, cultural).

- Un considerable número de países fueron colonizados por España.

- Existencia de una base o cultura jurídica proveniente del derecho romano (Como ejemplo de esta aplicación está el Derecho indiano aplicado en toda la región).

- Compromiso internacional relacionado con la protección de los derechos humanos.

- Marco institucional de corte liberal inspirado en el constitucionalismo norteamericano.

Autores como Fernández (1999) han venido señalando que uno de los efectos de esta dinámica histórica es la paradoja existente entre la urgencia de armonización y unificación y la práctica jurídica, la cual se encuentra enmarcada por un particularismo que impone barreras muy difíciles de manejar por parte de los Estados:

Este fenómeno no es otra cosa que expresión del aumento y de la diversidad de organizaciones estatales, extraestatales o paraestatales y tiene la virtud de dar como resultado una cada vez más frecuente contradicción entre dos o más ordenamientos jurídicos respecto a un mismo hecho, acto, relación o situación jurídica. (Fernández, 1999, p. 17)

De acuerdo con este autor, el pluralismo jurídico lleva a que se presenten contradicciones en la reglamentación, afectando con ella los derechos y deberes de las personas, en la medida que se muestra un vacío jurídico que genera inseguridad 
jurídica a la hora de abordarlos el operador judicial. Ahora, si este pluralismo jurídico, en el ámbito del derecho privado, se lleva a la esfera internacional, requiere que estos sean asumidos por el derecho internacional privado (Sánchez, 2006).

Es de precisar, tal como lo recuerda Suárez (2012) que la unificación y armonización del derecho privado ha sido una de las constantes búsquedas y conflictos en los cuales se ha visto confrontada la doctrina, ya que implica necesariamente que se establezcan unos principios universales que logren su cobertura global y cobre la validez suficiente en el tráfico de los negocios internacionales.

A este desarrollo histórico Wilson (2007) suma los esfuerzos y acciones emprendidas por la Organización de Estados Americanos (OEA) a partir de 1975, lo que ha permitido que haya jugado un papel preponderante en la consolidación, codificación y armonización del derecho internacional privado en la región, materializándose en las Conferencias Especializadas Interamericanas sobre Derecho Internacional Privado (CIDIP) cuyo principal interés ha sido la creación de instrumentos jurídicos internacionales de profunda importancia para los Estados.

En total se han proyectado un total de 26 instrumentos que han sido adoptados por los Estados miembros de la OEA, de los cuales 21 se encuentran en pleno vigor: "Mientras la región marcha hacia una etapa de mayor integración económica, la importancia del proceso de CIDIP se acentúa por el crecimiento en el movimiento transfronterizo de personas, bienes y servicios. Esta interdependencia requiere de mayor armonización y estandarización del derecho internacional privado" (Wilson, 2007, p. 329). Este autor señala los siguientes instrumentos o convenciones:

En la CIDIP-I, se plantearon y adoptaron las siguientes temáticas 1) Conflictos legales relativos a las letras de cambio, pagarés y facturas; 2) Conflictos concernientes a los cheques; 3) Arbitraje comercial internacional; 4) Exhortos o cartas rogatorias; 5) Recepción y validación de pruebas; y 6) Calidad de los poderes usados en el extranjero. En el CIDIP-II (1979) fueron siete los aspectos tratados, la mayoría de ellos en relación con el derecho mercantil y el derecho procesal internacional. Estos instrumentos fueron: 1) Tratamiento de los conflictos relativos a cheques; 2) Conflictos de leyes para el tratamiento de las sociedades mercantiles; 3) Valor y eficacia extraterritorial de las sentencias y laudos arbitrales impulsado en el extranjero; 4) Ejecución de medidas preventivas; 5) Material probatorio e información con respecto al derecho extranjero; 6) Definición del domicilio de las personas físicas en el derecho internacional privado; 7) Identificación de las normas generales de derecho internacional privado; y 8) Manejo de los exhortos y cartas rogativas (Wilson, 2007). 
En el CIDIP-III, desarrollado en 1984, se trataron temas relativos a la adopción de menores, personalidad y capacidad de las personas jurídicas, competencia y eficacia de las sentencias extranjeras y recepción de pruebas en el extranjero. La CIDIP-IV se enfocó principalmente en temas como la restitución internacional de menores, las obligaciones alimentarias y la contratación de transporte internacional de mercaderías por carretera. A estas conferencias se han sumado otras tres, llamando la atención la celebrada en el 2002, en la cual se abordó el tema de la armonización en materia de garantías inmobiliarias.

Esta dinámica de la OEA, señalada por Wilson (2007), muestra la diversidad de exigencias normativas orientadas a la armonización en tiempos de la globalización y de las Tecnologías de la Información y de las Comunicaciones (TIC) lo que sin duda muestra que se quiere fortalecer un derecho acorde a los tiempos actuales. Esto es evidente en el desarrollo de las últimas conferencias en donde se manejaron aspectos clave como la protección al consumidor, los registros electrónicos, impulso a los estudios paralelos que requieren de un consenso para elaborar un instrumento internacional.

A dos siglos de estas iniciativas, el panorama frente a este tema sigue vigente y cobra fuerza, no tanto por la acción o iniciativa de los diferentes gobiernos en la región, sino por las implicaciones que tiene la globalización en el tráfico jurídico, con lo que se da a entender cómo el derecho se encuentra supeditado a la dinámica de la sociedad que, con un paso adelante, va indicando el camino que debe tomar aquél.

De otro lado, desde la doctrina, autores como Garro (1992) ya venían insistiendo en la necesidad de armonización y unificación del derecho privado en la región, aduciendo que además de los factores históricos señalados anteriormente, se ha desarrollado una vocación internacional que procura este tipo de acciones e iniciativas, siendo las más relevantes la Conferencia de Derecho Internacional Privado en la Conferencia de La Haya; la creación de la Comisión de las Naciones Unidas para el Derecho Mercantil Internacional (CNUDMI ó UNCITRAL) y la instauración del Instituto para la Unificación del Derecho Privado (UNIDROIT).

En síntesis, se observa cómo el contexto histórico de la armonización normativa en América Latina se encuentra marcado por una multiplicidad de acciones e intenciones, pero las mismas no se han logrado consolidar debido a intereses propios de cada uno de los Estados; pero que dada la incidencia de la globalización, se requiere de una voluntad por parte de estos y de un apoyo de organismos internacionales que lo puedan avalar. 


\section{Elementos esenciales para lograr la armonización del Derecho privado en América Latina}

Para entender y asumir el análisis de estos elementos de armonización del derecho privado en América Latina es de suma importancia tener en cuenta experiencias en esta dirección, como es el caso de la Unión Europea, que viene desarrollando dicho proceso por más de tres décadas a través de la participación activa de juristas, doctrinantes y académicos europeos, la cual se ha materializado en el "Proyecto de Marco Común de Referencia ('Draft Common Frame of Reference' [DCFR]), que contiene principios, definiciones, reglas-modelo de derecho civil, contractualy de responsabilidad civil, con disposiciones de contratos mercantiles y de consumo" (Muriel, 2012, p. 358).

Este proyecto es solo una muestra de la constante actividad desarrollada en la Unión Europea por llevar a cabo un proceso eficiente de armonización, siendo evidente que él mismo se construyó bajo dos pilares fundamentales: la formación de un mercado interior basado en la promoción y su adecuado funcionamiento, de forma que permita que se establezca una notable circulación de bienes, personas y servicios; en segundo lugar, se encuentra la protección de los consumidores, como ejes de la dinámica del mercado regional (Momberg, 2009).

Para este autor, ha sido indudable el papel de la Comisión de las Comunidades Europeas, que como órgano ejecutivo ha logrado impulsar la creación no solo de instrumentos jurídicos que armonizan el derecho privado, sino en la construcción de una cultura jurídica basada en directivas, comunicaciones y documentos que abordan cada una de las iniciativas o problemas a resolver. Aun así, considera que no se puede hablar de la existencia una armonización general en aspectos muy específicos como el Derecho contractual, ya que considera que se ha limitado demasiado hacia el Derecho de consumo, dejando al margen otros de significativa importancia.

Desde otro punto de vista, Sánchez (2008) plantea cómo el proceso de armonización normativa del derecho privado en la Unión Europea se enfoca a ciertos aspectos pero no a la totalidad del mismo: "contratos celebrados por consumidores, aprovechamiento por turno de bienes inmuebles, mora en las transacciones comerciales, responsabilidad derivada de productos defectuosos, transferencias internacionales, contratos de seguro, contratos de trabajo, contratos de agencia, comercio electrónico, propiedad intelectual” (p. 379). 
Además del desarrollo del derecho privado europeo, no se puede dejar al margen la labor y esfuerzos del Instituto Internacional para la Unificación del Derecho Privado (Unidroit) del cual hacen parte un total de 63 países, que representan y dialogan en torno a la diversidad y pluralidad de costumbres, leyes y sistemas económicos vigentes; de ahí que representen un punto de vista sólido para identificar los criterios sobre armonización normativa en el derecho privado (Castro, 2009).

Es en ese sentido que Unidroit plantea en su seno cinco tareas o acciones orientadas al fortalecimiento de la legislación interna de los Estados en materia de derecho privado. Estas acciones son:

a. Prepara proyectos de leyes o convenciones con miras a establecer un derecho interno uniforme;

b. Prepara proyectos de acuerdos tendientes a facilitar las relaciones internacionales en materia de derecho privado;

c. Emprende estudios de derecho comparado en materia de derecho privado;

d. Se interesa por las iniciativas ya tomadas por otras instituciones en todos esos campos con las cuales puede, en caso necesario, mantenerse en contacto;

e. Organiza conferencias y publica los estudios que juzga dignos de amplia difusión. (Castro, 2009, p. 72)

Los resultados de estas acciones se han materializado en la modificación de las leyes internas en los Estados (no en todos pero sí en la mayoría) y en la consolidación de cuatro convenciones que han unificado el derecho privado: formación de contratos para la venta internacional de mercaderías, arrendamiento financiero internacional, factoraje internacional y objetos culturales robados o ilegalmente importados (Castro, 2009).

Analizados los aportes desde el derecho privado europeo y de la Unidroit, valga decir que para hablar de armonización en el derecho privado en América Latina es necesario, según Bermúdez (2006), tener en cuenta tres parámetros que tienen incidencia notable como son la diversidad legislativa de las naciones conforme a la pluralidad cultural; la unificación de normas jurídicas en América Latina; y el proceso de globalización. Estos parámetros deben articularse de tal forma que permitan identificar los principios sobre los cuales se puede llevar a cabo.

Profundizando, Tito (2013) plantea que deben existir una serie de prerrequisitos, siendo uno de ellos la cultura jurídica en la región, ya que debe existir en el ámbito de los operadores jurídicos, juristas y doctrinantes una clara intención por 
unificar el derecho: "Un argumento que rompe esta inmovilización del derecho es, desde nuestra óptica, la creación de una cultura jurídica común latinoamericana, que no es en rigor normativa, sino valorativa desde el ámbito de la labor de los juristas" (p. 264).

Esta valoración se explica en el sentido de que los cambios orientados a un derecho privado latinoamericano no se encuentran en manos del legislador, sino de la construcción de una cultura y espíritu jurídico común, en el cual se contemple la inclusión de los innumerables vértices de la dispersión jurídica imperante en que se encuentran los países en la región.

Desde otra perspectiva, Tito (2013) aboga por que la armonización del derecho privado se dé en la esfera de la "unidad en la diversidad", lo que se materializa en un "modelo de integración jurídico-flexible o lo que es igual, en un modelo de complejidad que adapta las mutaciones que sufre el derecho dentro de un sistema y entorno jurídico siempre heterogéneos" (p. 248).

Según este autor, para desarrollar tal modelo se requiere previamente la creación de Estructuras de Derecho (ED) o lo que es lo mismo Estándares Jurídicos a Armonizar (EJA) que procuren la estabilidad al momento de sentar una plataforma gnoseológica que pueda hacer que recaían en ella todas aquellas convergencias y divergencias que estén presentes al momento de discutir el proceso de armonización (Tito, 2013).

No obstante a estos parámetros, se identifican como principales vacíos o limitantes que interfieren en la armonización y unificación del derecho privado:

- La noción misma: Institución del orden público expresado en la tradición jurídica de los tribunales.

- La interpretación liberal: Enunciada en la formación de los abogados y de los operadores judiciales, la cual se encuentra delimitada a un Estado.

- La metodología utilizada en la construcción e interpretación del derecho parte de los operadores judiciales.

- La falta de integración en América Latina en aspectos fundamentales como el económico, pues si es irreal la integración económica, igualmente es irreal cualquier posibilidad de integración del derecho privado (Tito, 2013).

Asimismo, retomando la importancia de las conferencias creadas por la OEA, a través del CIDIP, vale decir que su incidencia radica en haber creado instrumentos de cooperación orientados a la aplicación y desarrollo del derecho internacional privado, en los cuales se identificaron las siguientes actividades o criterios: creación de una red 
de autoridades centrales que orienten e impulsen la asistencia legal mutua (permite la facilitación de comunicaciones, cooperación entre los gobiernos, capacitación de funcionarios, formular recomendaciones de asistencia legal); cooperación en materia de derecho civil (manejo de litigios internacionales, manejo de la restitución de menores); cooperación sobre convenciones en materia procesal, familiar y comercial (aplicación de las convenciones interamericanas) (Wilson, 2007).

Estos instrumentos sin duda coadyuvan en el objetivo central como es la creación de una red de autoridades y funcionarios que propicien la armonización normativa en aspectos vitales del derecho privado internacional, el cual necesariamente deberá estar acompañado de una guía de buenas prácticas que permita facilitar las acciones encaminadas a este objetivo.

\section{Conclusiones}

Cabe destacar que la globalización como fenómeno político, económico, cultural, social y jurídico, ha contribuido de forma determinante en la búsqueda de instrumentos jurídicos regionales que impulsen la armonización del derecho privado en América Latina, pues si bien se cuenta con instrumentos internacionales, como los expresados a través de la Unidroit, es claro que los factores culturales en esta región invitan a desarrollar instrumentos más acordes con su práctica jurídica, de ahí que los esfuerzos dados por la OEA son significativos siempre y cuando entren en vigencia y se puedan aplicar.

Finalmente, vale decir que estos instrumentos necesariamente tendrán que tener la coherencia necesaria para aplicarse en entornos más globales, en donde sin duda el papel de Unidroit y la ONU tienen mucho que decir y aportar en el proceso de normalización normativa global del derecho privado.

\section{Referencias}

Álvarez, R., Giacalone, R. y Sandoval, J. M. (2002). Globalización, integración y fronteras en América Latina. Recuperado de http://www.comunidadandina.org/bda/docs/VEINT-0001.pdf 
Bermúdez, Y. (2006). La identidad nacional y la unificación de las normas jurídicas latinoamericanas en la globalización (pp. 125-140). Revista de Derecho. 25.

Castro, R. (2009). La unificación del derecho privado frente a la globalización (pp. 70-78). Revista Justicia Iuris. 6(12).

Fernández, J. (1999). Los procesos de unificación internacional del derecho privado: técnicas jurídicas y valoración de resultados. Revista Civitas. ISBN 84-470-1319-7.

García, R. (2002). Aproximación a los mecanismos alternativos de resolución de conflictos en América Latina. Recuperado de http://ilsa.org.co:81/biblioteca/dwnlds/od/elotrdr026-27/ elotrdr026-27-07.pdf

Garro, A. (1992). Armonización y unificación del derecho privado en América Latina: esfuerzos, tendencias y realidades (pp. 225-267). Revista del Derecho Comercial y de las Obligaciones. 22.

Momberg, R. (2009). Análisis crítico del proceso de armonización del derecho contractual en la Unión Europea (pp. 9-33). Revista de Derecho. 22(1).

Muriel, J. (2012). Contribuciones doctrinales a la armonización y el avance del derecho privado europeo (pp. 357-363). Revista de Derecho Privado. 22.

Sánchez, A. (2006). Los orígenes del pluralismo jurídico. México: Universidad Nacional Autónoma de México. Recuperado de http://biblio.juridicas.unam.mx/libros/4/1855/29.pdf

Sánchez, S. A. (2008). Vias y limites a la unificación del derecho privado europeo: soft law versus hard law o comisión contra parlamento. Recuperado de http://digibug.ugr.es/ bitstream/10481/13623/1/VIAS\%20Y\%20LIMITES\%20PARA\%20LA\%20UNIFICACION\%20DEL\%20DERECHO\%20PRIVADO\%20EUROPEO.pdf

Serna, J. M. (2007). Hacia una visión integral del sistema federal mexicano: descentralización, armonzación, unificación y colaboración. México: Universidad Nacional Autónoma de México. Recuperado de http://biblio.juridicas.unam.mx/libros/5/2389/26.pdf

Suárez, C. (2012). Eficacia de los principios de contratación en el proceso de unificación del Derecho Internacional Privado: comparación entre la unificación jurídica latinoamericana y la integración europea (pp. 43-100). Revista e-mercatoria. 11(1).

Tito, J. (2013). Hacia un modelo de armonización del derecho contractual Latinoamericano (pp. 239-267). Revista Vniversitas. 126.

Wilson, J. M. (2013). Introducción al Sistema Interamericano de Derecho Internacional privado: el proceso de la séptima conferencia especializada interamericana sobre derecho internacional privado(CIDIP-VII). Recuperado de http://www.oas.org/dil/esp/327-362\%20JWilson.pdf 